\title{
Carbon dioxide responsiveness in COPD patients with and without chronic hypercapnia
}

\author{
G. Scano*, A. Spinelli*, R. Duranti*, M. Gorini**, F. Gigliotti**, \\ P. Goti*, J. Milic-Emili
}

Carbon dioxide responsiveness in COPD patients with and without chronic hypercapnia. G. Scano, A. Spinelli, R. Duranti, M. Gorini, F. Gigliotti, P. Goti, J. Milic-Emili. OERS Journals Ltd 1995.

ABSTRACT: To ascertain whether and to what extent the reduced ventilatory response to a hypercapnic stimulus in chronic obstructive pulmonary disease (COPD) patients depends on a blunted chemoresponsiveness of central origin or to mechanical impairment, we studied two groups of COPD patients without (group A) and with (group B) chronic hypercapnia, but with similar degrees of airway obstruction and hyperinflation.

The study was performed on 17 patients (9 normocapnic and 8 hypercapnic). Six age-matched normal subjects (group C) were also studied as a control. During a $\mathrm{CO}_{2}$ rebreathing test, ventilation $\left(\dot{V}_{E}\right)$, mouth occlusion pressure $\left(\mathrm{P}_{0.1}\right)$, and the electromyographic activity of diaphragm (Edi) were recorded and then plotted against end-tidal carbon dioxide tension $\left(\mathrm{PCO}_{2}\right)$.

Inspiratory muscle strength was significantly lower in the hypercapnic group (group B) compared to normocapnic group (A), and in these groups compared to the control group (C). Both patient groups exhibited significantly lower $\Delta \dot{\mathbf{V}} / \Delta \mathbf{P C O}_{2}$ than the control group. In hypercapnics, $\Delta \mathbf{P} 0.1 / \Delta \mathbf{P C O}_{2}$ was significantly lower than in normocapnics and control group, whilst mouth occlusion pressure as \% of maximal inspiratory pressure $\Delta \mathbf{P} 0.1(\% \mathrm{MIP}) / \Delta \mathbf{P C O}_{2}$ did not differ significantly among the three groups. $\Delta \mathrm{Edi} / \Delta \mathrm{PCO}_{2}$ increased from $\mathrm{C}$ to $\mathrm{A}$. At a $\mathrm{PCO}_{2}$ of $8.65 \mathrm{kPa}, \dot{\mathrm{VE}}$ was similar in the normocapnic and control group, but lower in hypercapnics; Edi was similar in hypercapnic and control group; but greater in normocapnics. P0.1(\% MIP) did not differ significantly among groups.

Although these data seem to suggest that $\mathrm{CO}_{2}$ chemoresponsiveness was normal in hypercapnic and increased in normocapnic COPD patients, the lower $\dot{V}_{E}$ at a $\mathrm{PCO}_{2}$ of $8.65 \mathrm{kPa}$ casts doubts about the adequacy of chemoresponsiveness in the hypercapnic group. In the latter, the reduced $P 0.1$ response in face of normal Po.1(MIP) and Edi responses to carbon dioxide stimulation could suggest an impairment in inspiratory muscle function. Mechanical impairment and inadequate chemoresponsiveness are both likely to contribute to the low ventilatory response to $\mathrm{CO}_{2}$ stimulation in chronic hypercapnic COPD patients. Eur Respir J., 1995, 8, 78-85.

\author{
*Pulmonary Section, Dept of Interna \\ Medicine and **Fondazione Pro-Juventute \\ Don C. Gnocchi, Firenze, Italy. ${ }^{\dagger}$ Meakins- \\ Christie Laboratories, McGill University, \\ Montreal, Canada. \\ Correspondence: G. Scano \\ Istituto di Clinica Medica III \\ Università degli Studi di Firenze \\ Viale G.B. Morgagni 85 \\ 50134 Florence \\ Italy \\ Keywords: Chemoresponsiveness \\ chronic obstructive pulmonary disease \\ control of breathing \\ electromyography \\ mouth occlusion pressure
}

Received: November 61993 Accepted after revision August 271994

This work was supported by grants from the Ministero dell'Università e della Ricerca Scientifica e Tecnologica of Italy.
Since the original study by WHITELAW et al. [1], mouth occlusion pressure $\left(\mathrm{P}_{0.1}\right)$ has been found useful in assessing neuromuscular inspiratory drive in patients with chronic obstructive pulmonary disease (COPD) [210]. Based on the observation that $\mathrm{P}_{0.1}$ was greater in a group of hypercapnic COPD patients than in a group of less hyperinflated normocapnic patients, ŠoRLI et al. [8] hypothesized that the rate of the rise of phrenic electroneurogram or diaphragmatic electromyogram (Edi), an index of neural inspiratory drive, was greater in the former group. Current methods of electromyogram processing and quantification [11-13] make Edi a useful index of respiratory muscle activation, both in normal subjects and patients with chronic airflow obstruction [9, 11-21].
We have recently applied these methods and, consistent with the hypothesis of SorLi et al. [8], have shown that COPD patients with hypercapnia have a greater Edi compared to COPD patients with normocapnia [9].

Despite a high $\mathrm{P}_{0.1}$ whilst breathing room air, hypercapnic patients with COPD have been reported to have a blunted $\mathrm{P}_{0.1}$ responsiveness to exogenous carbon dioxide [3-8]. This pattern is consistent with a previous study by Lourenço and Miranda [22] showing that the Edi response to carbon dioxide tension $\left(\mathrm{PCO}_{2}\right)$ is remarkably low in hypercapnic COPD patients. Contrasting evidence, however, was given in a brief report by GRIBBIN et al. [14]. On the other hand, in many relevant papers $[8,10$, $14,22]$, the study group and the control group were not 
accurately matched for age and pulmonary mechanics. This shortcoming needs to be stressed because in assessing the relative importance of factors which affect the respiratory response to exogenous $\mathrm{CO}_{2}$ stimulation, differentiation of diminished carbon dioxide responsiveness of central origin from that due to mechanical impairment is an important issue of clinical relevance.

Therefore, the present investigation was aimed at evaluating the magnitude of chemoresponsiveness assessed in terms of Edi, $\mathrm{P}_{0.1}$ and ventilatory $\left(\dot{\mathrm{V}}_{\mathrm{E}}\right)$ responses to carbon dioxide stimulation in two groups of COPD patients with a similar degree of pulmonary mechanical impairment, one with chronic hypercapnia and the other with normocapnia. We have found that $\mathrm{CO}_{2}$ responsiveness is high in normocapnics, whilst in hypercapnics, though similar to that of normal control group, it is probably inadequate to sustain $\dot{\mathrm{V}} \mathrm{E}$.

\section{Materials and Methods}

\section{Subjects}

The study was performed on 17 patients with COPD as defined by the criteria of the American Thoracic Society [23]. Eight males and one female (group A), aged $64 \pm 4$ (SD) yrs, were normocapnic (arterial carbon dioxide tension $\left(\mathrm{PaCO}_{2}\right)<5.72 \mathrm{kPa}$ ); and eight males (group B) aged $67 \pm 4.4$ yrs were hypercapnic $\left(\mathrm{PaCO}_{2} \geq 6.25 \mathrm{kPa}\right)$. All patients complained of exertional dyspnoea. All had roentgenographic findings of pulmonary hyperinflation. At the time of the study, all patients were in a clinically stable state. Each had serial arterial blood gas measurements. Therapy was withheld for $12 \mathrm{~h}$ before the study. No patient exhibited a $>10 \%$ increase in forced expiratory volume in one second $\left(\mathrm{FEV}_{1}\right)$ after inhalation of a $\beta_{2}$-agonist bronchodilating agent. Patients with COPD and isolated episodes of $\mathrm{CO}_{2}$ retention due to acute exacerbation of bronchitis were excluded. We also studied an age-matched control group (C) of 6 normal subjects ( 3 males and 3 females) in whom lung function was within normal limits, aged $64 \pm 10$ yrs and height was $166 \pm 8 \mathrm{~cm}$. Informed consent was obtained from all subjects before the start of the experiments. All subjects were accustomed to the equipment and experimental procedure.

\section{Measurements}

Arterial blood gases and routine spirometry obtained in seated position were assessed as described previously [24]. The normal values for lung volumes are those proposed by European Community for Coal and Steel [25]. Maximal static inspiratory pressure (MIP) at functional residual capacity (FRC), measured against an obstructed mouthpiece with a small leak to minimize oral pressure artifacts, was measured using a differential pressure transducer (Statham SC 1001). The subjects, comfortably seated and wearing a noseclip, performed maximal inspiratory efforts and were instructed to maintain maximal pressures for at least $1 \mathrm{~s}$. The manoeuvres were repeated until three measurements with less than $5 \%$ variability were recorded. The highest value obtained was utilized for analysis.

The ventilatory pattern, inspiratory muscle activation, and mouth occlusion pressure were evaluated, with subjects in a comfortable supine position. In the apparatus used, the inspiratory line was separated from the expiratory line by a one-way valve (Hans-Rudolph) connected to a Fleisch No. 3 pneumotachograph. The flow signal was integrated into volume. From the spirogram we derived: inspiratory time $(\mathrm{TI})$, expiratory time $(\mathrm{TE})$, total time of the respiratory cycle (Ttot), and tidal volume $\left(\mathrm{VT}_{\mathrm{T}}\right.$. Respiratory frequency $\left(f_{R}=60 /\right.$ Ttot $)$ and instantaneous ventilation $\left(\dot{\mathrm{V}}_{\mathrm{E}}=\mathrm{V}_{\mathrm{T}} \times f_{\mathrm{R}}\right)$ were also calculated. Mouth pressure during $\mathrm{CO}_{2}$ rebreathing was measured using a pressure transducer (Statham P23ID). Mouth occlusion pressure $0.1 \mathrm{~s}$ after the beginning of inspiration $\left(\mathrm{P}_{0.1}\right)$ [1] was recorded as described previously (9, 15-17). Mouth occlusion pressure was expressed both as absolute value $\left(\mathrm{cmH}_{2} \mathrm{O}\right)$ and as percentage of MIP, in order to normalize $\mathrm{P} 0.1$ for the individual differences in inspiratory muscle strength $[9,26]$. Expired $\mathrm{CO}_{2}\left(\mathrm{PCO}_{2}\right)$ was sampled continuously at the mouth by an infra-red $\mathrm{CO}_{2}$ meter. The dead space of the equipment was $178 \mathrm{ml}$ and the resistance of the system up to a flow of $4 l \cdot \mathrm{s}^{-1}$ was 0.92 $\mathrm{cmH}_{2} \mathrm{O} \cdot l \cdot \cdot^{-1} \cdot \mathrm{s}$.

The electromyographic activity of the diaphragm (Edi) was recorded as described previously [9, 15-17] via large surface electrodes from the lower anterolateral rib cage [27].

The muscle action potentials were differentially amplified, filtered between 100 and $1,000 \mathrm{~Hz}$, to remove as much electrocardiographic (ECG) activity as possible, without significantly filtering Edi. The filtered Edi signal and mouth pressure recording were displayed on a singlebeam storage oscilloscope (Tektronix 5115). Edi activity was full-wave rectified and integrated over time (time constant $100 \mathrm{~ms}$ ) using a third-order low-pass filter to provide a measurement of change in average electrical activity as a function of time, referred to as "moving time average" [11-13]. Inspiratory activity was quantified both as peak of activity and as rate of rise of activity. The former was directly measured in arbitrary units (XP), and the latter was obtained by dividing XP by the inspiratory time $\left(\mathrm{XP} / \mathrm{TI}_{\mathrm{I}}\right)$.

Because of the variability of the impedance between diaphragm and electrodes, absolute values $(\mathrm{mV})$ are not comparable among different subjects. To overcome this problem and to obtain a reference value, Edi was measured whilst the subject, connected to the pneumotachograph, performed an inspiratory manoeuvre breathing in up to total lung capacity (TLC) [28]. This manoeuvre was repeated at least three times, and in each subject both inspiratory volume and the peak of Edi were closely reproducible (less than 5\% variability). The mean level of this Edi activity was taken as a reference; all successive measurements have been expressed as a percentage of the reference value obtained at TLC. Since the EMG activity of inspiratory muscles may include cardiac activity, 
we checked cardiac artifacts to manually gate ECG, if necessary, so that it would not contribute substantially to the Edi.

The output of the $\mathrm{CO}_{2}$ meter, flow signal, integrated flow signal, mouth pressure, and the moving time average were recorded continuously on a multichannel chart recorder. Respiratory cycles, occlusions and Edi were continuously recorded, and the cycles immediately following each occlusion were discarded. Ventilatory parameters and Edi were calculated from the data averaged from the three breaths preceding each occlusion.

\section{Protocol}

After a $10 \mathrm{~min}$ adaptation period, baseline evaluation began. Successively, the subjects underwent a $\mathrm{CO}_{2}$ rebreathing test following the procedure recommended by READ [29]. A gas mixture $\left(7 \% \mathrm{CO}_{2}\right.$ and $\left.93 \% \mathrm{O}_{2}\right)$ was inhaled for 3-5 min from a 5-8 $l$ bag, the largest bag being reserved for normal subjects. In all cases, the gas volume administered exceeded the subject's vital capacity by $1 \mathrm{l}$. Using these values, the rebreathing bag was kept flaccid. Rebreathing started after 30-45 s, which allowed the subject to equilibrate with the circuit as shown by the plateau on the $\mathrm{CO}_{2}$ record and minimal $\mathrm{PCO}_{2}$ inspiratory/ expiratory swings. Details of the technique have been reported previously [30]. In each normal subject, the rebreathing test was repeated on 2-3 different days, whilst in patients it was duplicated on the same day with an interval of $60 \mathrm{~min}$ between each test. The resistance of the circuit used during the $\mathrm{CO}_{2}$ rebreathing test was such that the mouth pressure during unoccluded breathing was always $<2 \mathrm{cmH}_{2} \mathrm{O}$ greater than or less than atmospheric pressure. During $\mathrm{CO}_{2}$ inhalation, when the open-loop condition was achieved, occlusions were randomly performed every 10-20 s.

In normal subjects and in COPD patients, peak moving average at TLC remained fairly constant from the start to the end of the $\mathrm{CO}_{2}$ rebreathing run ( $\sim 5$ to $\left.10 \%\right)$. Therefore, it was used to normalize Edi recorded at VT.

\section{Data analysis}

For each rebreathing run, changes in $\dot{V} E$, timing and volume components of breathing pattern, $\mathrm{P}_{0.1}$ and Edi were plotted against corresponding $\mathrm{PCO}_{2}$ values [9, 15-17] and subjected to least square linear regression analysis. We made sure that in no case was the response exhibited on one study $20 \%$ greater or lower than the response on each of the other studies.

For each normal subject and for each patient mean slope for three or two runs, respectively, was calculated; data were averaged for patients and normal subjects.

Values are mean \pm SD. Spirometric and arterial blood gas values were compared between normocapnic and hypercapnic patients by means of Mann-Whitney U test for unpaired samples. All other results were compared by Kruskal-Wallis analysis of variance (KWAV) and Mann-Whitney $U$ test when appropriate. A value of $\mathrm{p}<0.05$ was considered significant. Bonferroni's adjustment $(0.05 / \mathrm{n}$ tests) for multiple testing was used.

\section{Results}

The anthropometric characteristics and respiratory function data of the patients are summarized in table 1 . Age was not significantly different in the three groups; the body weight, expressed as percentage of the ideal weight [31], was $93.3 \pm 12 \%, 95.3 \pm 9.5 \%$ and $105 \pm 7 \%$ for groups $\mathrm{A}, \mathrm{B}$ and $\mathrm{C}$, respectively. The two patient groups also showed similar values of vital capacity (VC), and a similar degree of airway obstruction $\left(\mathrm{FEV}_{1}\right)$ and hyperinflation (FRC). MIP differed significantly among the three groups $(\mathrm{p}<0.0008)$; in groups $\mathrm{A}$ and $\mathrm{B}, \mathrm{MIP}$ was significantly lower $(\mathrm{p}<0.05)$ compared to the control group $\left(\mathrm{C} 91.6 \pm 19 \mathrm{cmH}_{2} \mathrm{O}\right)$, and in group $\mathrm{B}$ it was significantly lower than in group A. Arterial oxygen tension $\left(\mathrm{PaO}_{2}\right)$ was significantly lower $(\mathrm{p}<0.009)$ in group $\mathrm{B}$ compared to group A. Arterial $\mathrm{pH}$ was similar but arterial bicarbonate $\left(\mathrm{HCO}_{3}{ }^{-}\right)$content was higher in group B $(\mathrm{p}<0.0006)$.

As shown in table $2, \Delta \dot{\mathrm{V}} \mathrm{E} / \Delta \mathrm{PCO}_{2}$ was significantly lower in $\mathrm{A}$ and $\mathrm{B}$ compared to $\mathrm{C}(\mathrm{p}<0.024$ and $\mathrm{p}<0.01$, respectively). $\Delta \mathrm{P}_{0.1} / \Delta \mathrm{PCO}_{2}$ was significantly lower in $\mathrm{B}$ compared to $\mathrm{A}(\mathrm{p}<0.02)$ and $\mathrm{C}(\mathrm{p}<0.05)$, whilst $\Delta \mathrm{P}_{0.1}$ $(\% \mathrm{MIP}) / \Delta \mathrm{PCO}_{2}$ and $\Delta \mathrm{XP} / \Delta \mathrm{PCO}_{2}$ did not differ among the three groups (KWAV). In contrast, $\Delta(\mathrm{XP} / \mathrm{TI}) / \Delta \mathrm{PCO}_{2}$ increased from $\mathrm{C}$ to $\mathrm{A}(\mathrm{p}<0.028, \mathrm{KWAV})$ with a trend to be greater in $\mathrm{A}$ than in $\mathrm{C}(\mathrm{p}<0.063)$.

Individual data analysis (table 3 and fig. 1) show that in all patients but one (No. 17) the correlations of both $\mathrm{XP}$ and $\mathrm{XP} / \mathrm{T}$ I with $\mathrm{PCO}_{2}$ were significant. In patient No.

Table 1. - Anthropometric characteristics and pulmonary function data of the patients with COPD with normocapnia (group A) and chronic hypercapnia (group B)

\begin{tabular}{lrcrrr}
\hline & \multicolumn{2}{c}{$\begin{array}{c}\text { Group A } \\
\mathrm{n}=9\end{array}$} & \multicolumn{2}{c}{$\begin{array}{c}\text { Group B } \\
\mathrm{n}=8\end{array}$} & $\mathrm{p}$ \\
\hline Age yrs & 64 & $(4)$ & 67 & $(4)$ & $\mathrm{NS}$ \\
Weight \% IW & 93 & $(12)$ & 95 & $(9.5)$ & $\mathrm{NS}$ \\
VC* \% & 72 & $(8.2)$ & 63 & $(11)$ & $\mathrm{NS}$ \\
$\mathrm{RV}^{*} \%$ & 185 & $(34)$ & 203 & $(27)$ & $\mathrm{NS}$ \\
$\mathrm{FRC}^{*} \%$ & 157 & $(22)$ & 166 & $(20)$ & $\mathrm{NS}$ \\
$\mathrm{TLC}^{\circ} \%$ & 114 & $(15)$ & 113 & $(12)$ & $\mathrm{NS}$ \\
$\mathrm{FEV}_{1} \%$ & 32 & $(7.9)$ & 27 & $(8.7)$ & $\mathrm{NS}$ \\
$\mathrm{FEV}_{1} / \mathrm{VC} \%$ & 34.7 & $(8.4)$ & 30 & $(4.8)$ & $\mathrm{NS}$ \\
$\mathrm{MIP}_{\mathrm{cmH}} \mathrm{O}$ & 62.9 & $(15.5)$ & 46 & $(10)$ & $<0.04$ \\
$\mathrm{PaO}_{2} \mathrm{kPa}$ & 10.15 & $(1.23)$ & 8.44 & $(1.05)$ & $<0.009$ \\
$\mathrm{PaCO}_{2} \mathrm{kPa}$ & 5.18 & $(0.42)$ & 6.86 & $(0.74)$ & $<0.0006$ \\
$\mathrm{pH}^{\mathrm{HCO}}$ & 7.40 & $(0.013)$ & 7.39 & $(0.027)$ & $\mathrm{NS}$ \\
$\mathrm{HCO}_{3}-\mathrm{mEq} \cdot l^{-1}$ & 25.3 & $(1.3)$ & 30.8 & $(1.9)$ & $<0.006$ \\
\hline
\end{tabular}

Values are presented as mean and SD in parenthesis. VC: vital capacity; RV: residual volume; FRC: functional residual capacity; TLC: total lung capacity; $\mathrm{FEV}_{1}$ : forced expiratory volume in one second; MIP: maximal inspiratory pressure; $\mathrm{PaO}_{2}$ : arterial oxygen tension; $\mathrm{PaCO}_{2}$ : arterial carbon dioxide tension; $\mathrm{HCO}_{3}$ : arterial bicarbonate content; NS: nonsignificant; *: percentage of predicted value. Mann-Whitney U-test for unpaired samples was used in all comparisons but Age and MIP, in which Kruskal-Wallis analysis of variance and Mann-Whitney UTest with Bonferroni's adjustment were used. 
Table 2. - Average $\dot{\mathrm{V}}_{\mathrm{E}}, \mathrm{P}_{0.1}$ and Edi response slopes to hypercapnic rebreathing in patients and in normal subjects

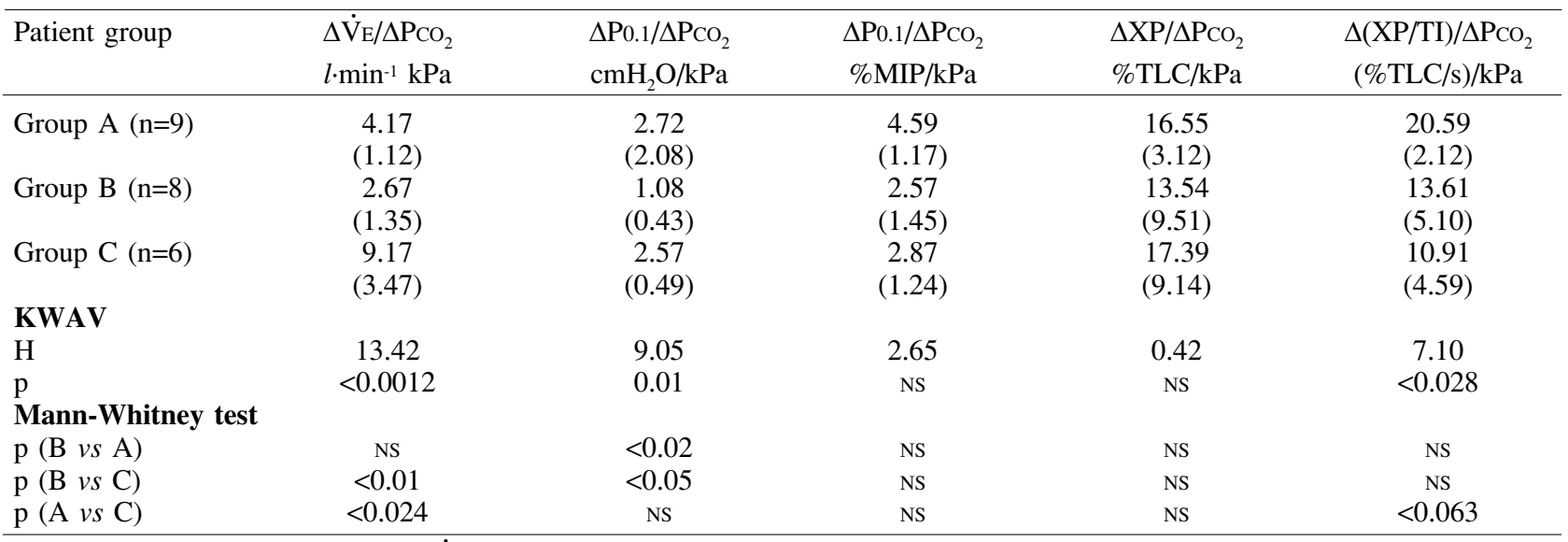

Values are presented as mean $( \pm \mathrm{SD})$. $\dot{\mathrm{V}}_{\mathrm{E}}$ : minute ventilation; $\mathrm{P} 0.1$ : mouth occlusion pressure; XP: peak of electromyographic activity of diaphragm; XP/TI: rate of rise of electromyographic activity of diaphragm, obtained by dividing XP by inspiratory time (TI); $\mathrm{PCO}_{2}$ : end-tidal pressure of carbon dioxide; KWAW: Kruskal-Wallis analysis of variance. For further abbreviations see legend to table 1.

17, XP reached a plateau during hypercapnia, indicating that the rise of XP/Ti. With increasing $\mathrm{PCO}_{2}$ was due to a decrease in TI with the exception of this patient, the $\mathrm{XP} / \mathrm{T} \mathrm{I}$ response slopes in COPD were similar to or greater than the average $\pm 1 \mathrm{SD}$ response slope of this relationship calculated for the control group. In contrast, in six group B patients (Nos 11, 13-17), and in one of group A (No. 9), the $\mathrm{P}_{0.1}$ response slopes were lower than the average $-1 \mathrm{SD}$ resonse slope of this relationship calculated for the control group (table 3 and fig. 2).

Table 4 shows that at $\mathrm{PCO}_{2}$ of $8.65 \mathrm{kPa}, \dot{\mathrm{V}} \mathrm{E}(\mathrm{p}<0.005)$, TI $(\mathrm{P}<0.003), \mathrm{XP}(\mathrm{p}<0.0028)$ and XP/TI $(\mathrm{p}<0.0018)$, but

Table 3. - Individual $\mathrm{P}_{0.1}$ and Edi response slopes to hypercapnic rebreathing in the two groups of COPD

\begin{tabular}{|c|c|c|c|c|c|c|}
\hline \multirow[t]{2}{*}{$\begin{array}{l}\text { Patient } \\
\text { No. }\end{array}$} & \multicolumn{2}{|c|}{$\begin{array}{l}\Delta \mathrm{P} 0.1 / \Delta \mathrm{PCO}_{2} \\
\mathrm{cmH}_{2} \mathrm{O} / \mathrm{kPa} \\
\end{array}$} & \multicolumn{2}{|c|}{$\begin{array}{l}\Delta \mathrm{XP} / \Delta \mathrm{PCO}_{2} \\
\% \mathrm{TLC} / \mathrm{kPa} \\
\end{array}$} & \multicolumn{2}{|c|}{$\begin{array}{c}\Delta(\mathrm{XP} / \mathrm{TI}) / \Delta \mathrm{PCO}_{2} \\
(\% \mathrm{TLC} / \mathrm{s}) / \mathrm{kPa} \\
\end{array}$} \\
\hline & $\mathrm{s}$ & $r$ & $\mathrm{~s}$ & $\begin{array}{l}\mathrm{r} \\
\mathrm{s}\end{array}$ & $\mathrm{s}$ & $\mathrm{r}$ \\
\hline \multicolumn{7}{|c|}{ Group A } \\
\hline 1 & 3.684 & 0.82 & 7.218 & 0.78 & 13.609 & 0.84 \\
\hline 2 & 3.458 & 0.99 & 23.83 & 0.88 & 28.947 & 0.93 \\
\hline 3 & 1.879 & 0.90 & 7.894 & 0.92 & 14.887 & 0.94 \\
\hline 4 & 7.744 & 0.95 & 32.330 & 0.71 & 23.609 & 0.88 \\
\hline 5 & 1.128 & 0.86 & 23.300 & 0.83 & 25.563 & 0.95 \\
\hline 6 & 1.428 & 0.94 & 11.128 & 0.95 & 19.624 & 0.98 \\
\hline 7 & 1.729 & 0.99 & 23.380 & 0.91 & 25.263 & 0.86 \\
\hline 8 & 2.007 & 0.94 & 13.760 & 0.93 & 23.533 & 0.90 \\
\hline 9 & 1.473 & 0.80 & 6.075 & 0.83 & 10.285 & 0.84 \\
\hline \multicolumn{7}{|c|}{ Group B } \\
\hline 10 & 1.128 & 0.73 & 29.399 & 0.92 & 16.466 & 0.88 \\
\hline 11 & 0.376 & 0.79 & 13.609 & 0.85 & 11.353 & 0.73 \\
\hline 12 & 1.804 & 0.83 & 24.135 & 0.91 & 20.000 & 0.69 \\
\hline 13 & 0.977 & 0.37 & -1.428 & 0.94 & 4.361 & 0.93 \\
\hline 14 & 1.503 & 0.92 & 10.827 & 0.93 & 15.338 & 0.94 \\
\hline 15 & 0.902 & 0.90 & 11.128 & 0.93 & 14.210 & 0.85 \\
\hline 16 & 1.053 & 0.90 & 12.781 & 0.91 & 9.172 & 0.95 \\
\hline 17 & 0.902 & 0.84 & 7.895 & -0.18 & 18.045 & 0.69 \\
\hline
\end{tabular}

$\mathrm{s}$ and $\mathrm{r}$ : slopes and correlation coefficients, respectively, of the relationships of $\mathrm{P}_{0.1}, \mathrm{XP}$ and $\mathrm{XP} / \mathrm{T}$ I with $\mathrm{PCO}_{2}$ during rebreathing. For further abbreviations see legend to tables 1 and 2 .
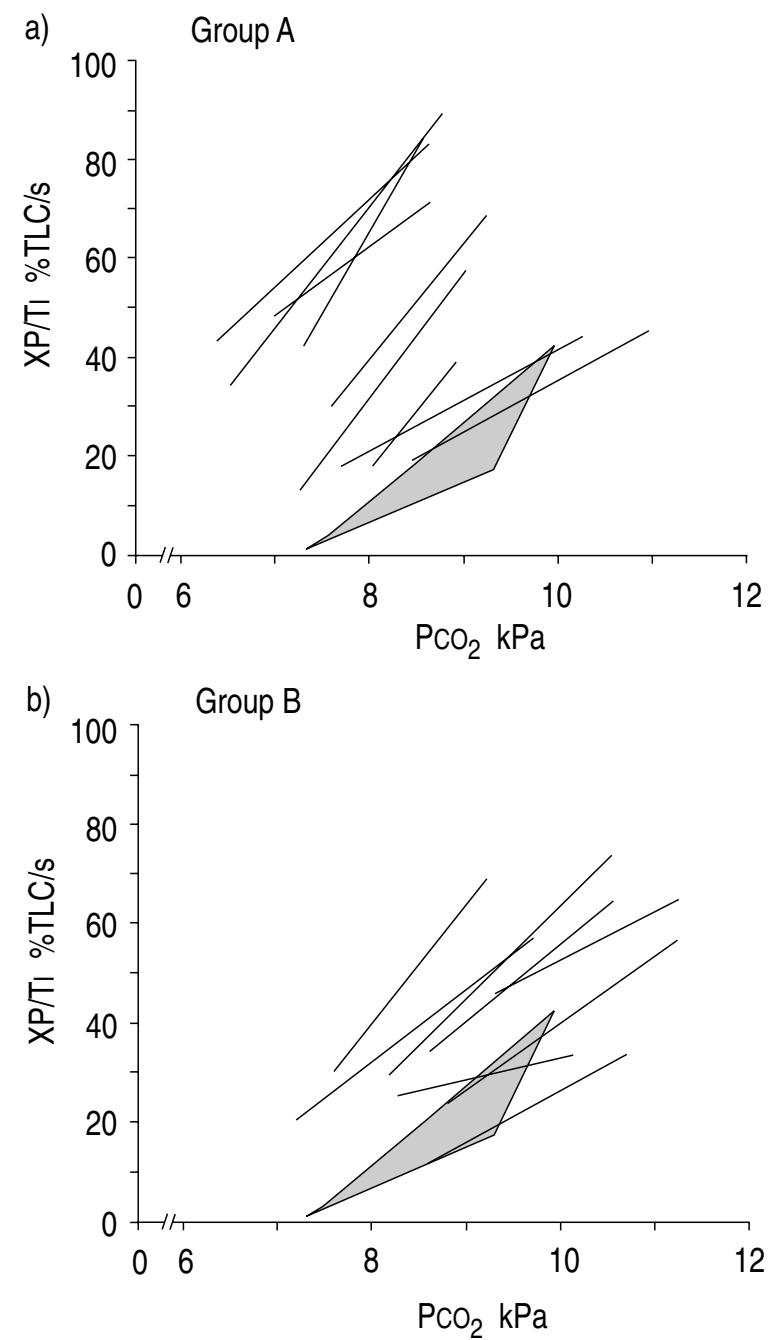

Fig. 1. - Individual plots of electromyographic activity of the diaphragm (Edi) activity (XP/TI) against end-tidal $\mathrm{PCO}_{2}$. Hatched area depicts normal mean response $\pm 1 \mathrm{SD}$ of slope. a) normocapnic (group A) patients. b) hypercapnic (group B) patients. XP: peak of electromyographic activity of diaphragm; XP/Tr: rate of rise of electromyographic activity of diaphragm obtained by dividing XP by inspiratory time (TI); TLC: total lung capacity; $\mathrm{PCO}_{2}$ : carbon dioxide tension. 

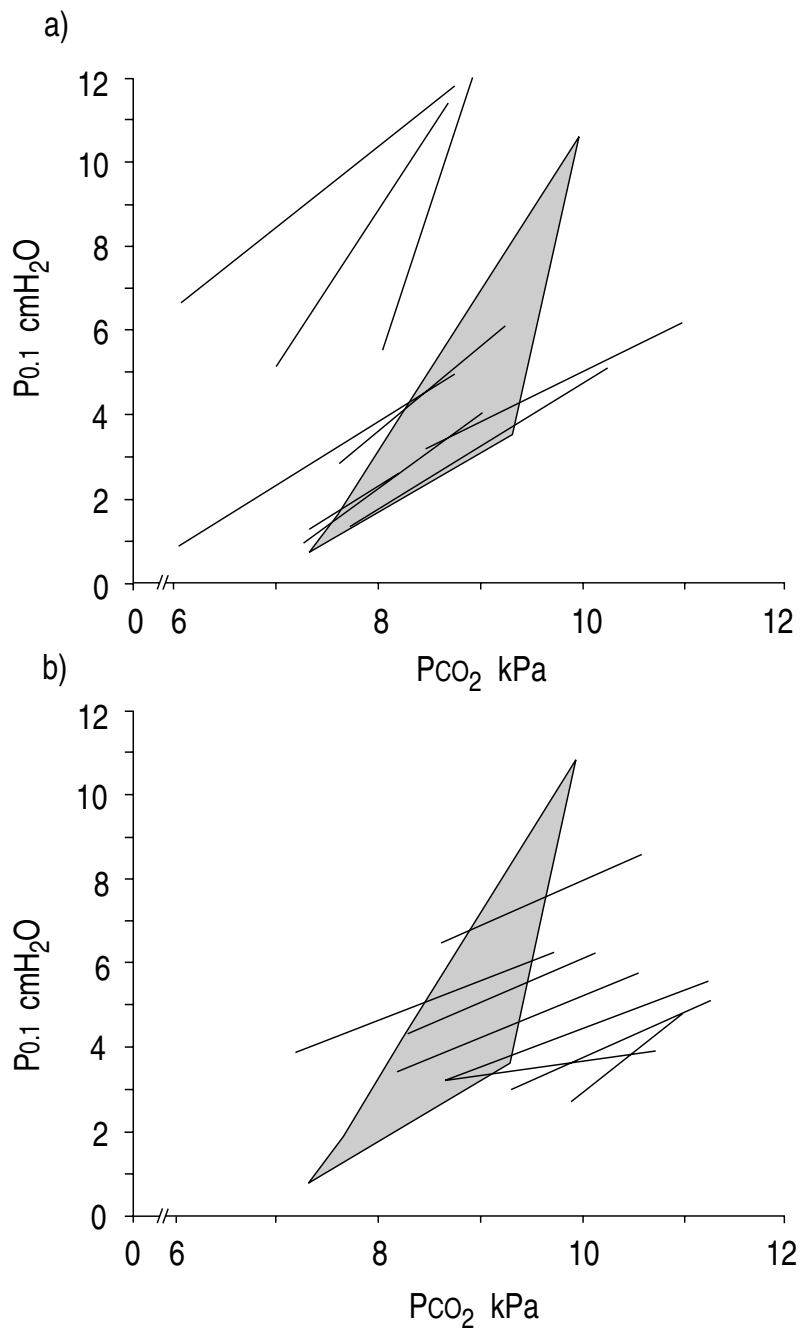

Fig. 2. - Individual plots of $\mathrm{P} 0.1$ against end-tidal $\mathrm{PcO}_{2}$. Hatched area depicts normal mean $\pm 1 \mathrm{sD}$ of slope. a) normocapnic (group A) patients; b) hypercapnics (group B) patients. P0.1: mouth occlusion pressure; $\mathrm{PCO}_{2}$ : carbon dioxide tension.

Table 4. - Ventilatory and Edi measurements at $\mathrm{PCO}_{2}$ of $8.65 \mathrm{kPa}$ in the three groups studied

\begin{tabular}{|c|c|c|c|c|c|}
\hline \multirow[t]{2}{*}{ Patient group } & $\dot{\mathrm{V}}_{\mathrm{E}}$ & TI & $\mathrm{P} 0.1$ & $\mathrm{XP}$ & $\mathrm{XP} / \mathrm{TI}$ \\
\hline & $l \cdot \mathrm{min}^{-1}$ & $\mathrm{~s}$ & $\% \mathrm{MIP}$ & $\% \mathrm{TLC}$ & $\% \mathrm{TLC} / \mathrm{s}$ \\
\hline \multirow[t]{2}{*}{ Group A $(n=7)$} & 20.71 & 1.01 & 10.89 & 55.3 & 56.6 \\
\hline & $(2.4)$ & $(0.17)$ & $(5.75)$ & (16) & $(22.2)$ \\
\hline \multirow[t]{2}{*}{ Group B $(n=6)$} & 13.50 & 1.16 & 8.99 & 35.3 & 30.01 \\
\hline & $(4.15)$ & $(0.27)$ & $(5.05)$ & $(11.4)$ & (13.7) \\
\hline \multirow[t]{2}{*}{ Group C $(n=6)$} & 25.5 & 1.74 & 5.33 & 25.0 & 22.6 \\
\hline & $(4.4)$ & $(0.66)$ & $(2.86)$ & $(9.90)$ & $(7.70)$ \\
\hline \multicolumn{6}{|l|}{ KWAV } \\
\hline $\mathrm{H}$ & 10.33 & 11.42 & 5.03 & 11.7 & 12.58 \\
\hline $\mathrm{p}$ & $<0.005$ & $<0.003$ & NS & 0.0028 & 0.0018 \\
\hline \multicolumn{6}{|c|}{ Mann-Whitney test } \\
\hline $\mathrm{p}(\mathrm{B} v s \mathrm{~A})$ & $<0.024$ & NS & - & NS & NS \\
\hline $\mathrm{p}(\mathrm{B} v s \mathrm{C})$ & $<0.05$ & NS & - & NS & NS \\
\hline $\mathrm{p}(\mathrm{A} v s \mathrm{C})$ & NS & $<0.005$ & - & $<0.008$ & $<0.005$ \\
\hline
\end{tabular}

Values are presented as mean \pm SD in parenthesis. For abbreviation see legend to tables 1 and 2 .

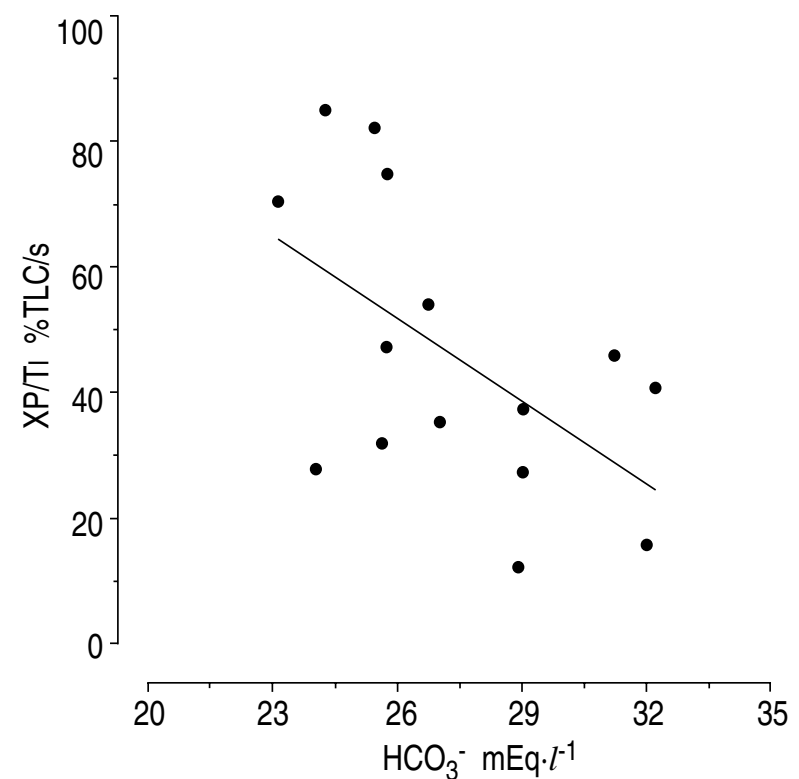

Fig. 3. - The figure depicts the relationship between $\mathrm{HCO}_{3}{ }^{-}$and Edi at $8.65 \mathrm{kPa}$. Individual data points are shown. $\mathrm{HCO}_{3}^{--}$arterial bicarbonate content. For further abbreviations see legend to figure 1 .

not P0.1(\%MIP) differed significantly among the three groups (KWAV). In general, both Edi variables showed a trend to increase from $\mathrm{C}$ to $\mathrm{A}$. In particular, $\mathrm{XP}$ was greater and $\mathrm{T}_{\mathrm{I}}$ lower in $\mathrm{A}$ than in $\mathrm{C}(\mathrm{p}<0.008$ and $\mathrm{p}<0.005$, respectively). As a consequence $\mathrm{XP} / \mathrm{T}$ I was significantly greater in $A$ than in $C(p<0.005)$.

$\mathrm{XP} / \mathrm{Tr}$ at a $\mathrm{PCO}_{2}$ of $8.65 \mathrm{kPaPCO}_{2}$ significantly correlated with arterial bicarbonate content obtained during room air breathing ( $\mathrm{r}=-0.5475 ; \mathrm{p}<0.034)$ (fig. 3$)$.

\section{Discussion}

In this study, we found a high chemoresponsiveness in normocapnic COPD patients, whereas in hypercapnic patients both mechanical impairment and an inadequate chemoresponsiveness were likely to play a role in the low ventilatory response to carbon dioxide stimulation.

In comparing the chemoresponsiveness in two groups of COPD patients we made sure they were accurately matched for age, anthropometric characteristics, and spirometric variables. The last point is mandatory if one wants to establish the relative contribution of pulmonary mechanics in the abnormalities in the control of breathing. The decrease in MIP noticed in COPD patients could depend on a number of factors. MIP is a voluntaly manoeuvre, and factors such as individual motivation and experience with test of respiratory muscle performance could explain, at least in part, the difference in MIP between the patient groups and the control group. However, none of the normal subjects had ever undergone respiratory muscle function tests, and all were unaware of the purposes of the study. Therefore, considering patient's co-operation and familiarity with the techniques, it is likely that the observed decrease in MIP reflects inspiratory muscle weakness.

During the $\mathrm{CO}_{2}$ rebreathing, consistent with previous studies $[2-5,7], \Delta \mathrm{VE} / \Delta \mathrm{PCO}_{2}$ was significantly smaller 
in groups $\mathrm{A}$ and $\mathrm{B}$ than in group $\mathrm{C}$. The slope of mouth occlusion pressure response to $\mathrm{CO}_{2}\left(\Delta \mathrm{P} 0.1 / \Delta \mathrm{PCO}_{2}\right)$ was smallest in group $\mathrm{B}$, in line with previous studies $3-5$, and in general accord with BRADLEY et al. [6]. In contrast, the results of GELB et al. [2] are different in that they did not observe substantial differences in $\Delta \mathrm{P}_{0.1} / \Delta \mathrm{PCO}_{2}$ between normocapnics and hypercapnics, half of whom did not differ from the control subjects. In the present study, we also expressed mouth occlusion pressure as percentage of MIP. Mouth occlusion pressure is an index that reflects both neural drive to, and the resulting force output of, the respiratory muscles [1]. Although $\mathrm{P}_{0.1}$ is a reasonable index of neural output to the respiratory muscles in normal subjects, in patients with respiratory muscle weakness (low MIP) P0.1 can underestimate the effective neuromuscular respiratory drive [32]. In order to take into account individual differences in inspiratory muscle strength, Peterson et al. [26] expressed $\mathrm{P}_{0.1}$ as percentage of MIP. Accordingly, the normalization of $\mathrm{P}_{0.1}$ for individual differences in muscle strength allows a more appropriate comparison of chemoresponsiveness between different groups of subjects $[9,26]$. In the present study, $\Delta \mathrm{P}_{0.1}(\% \mathrm{MIP}) / \Delta \mathrm{PCO}_{2}$ and $\mathrm{P} 0.1(\% \mathrm{MIP})$ at $8.65 \mathrm{kPa}$ did not differ among the three groups.

To our knowledge, only a few studies [14, 15, 21, 22] have dealt with Edi measurement of chemoresponsiveness to carbon dioxide in patients with COPD. In previous papers, we have thoroughly criticized the use of either surface or oesophageal EMG recording to assess respiratory drive in humans $[9,15,19,33-36]$. Nonetheless, many data in normal and in disease state support the contention that the slope of the moving time average $(\mathrm{Edi} / \mathrm{TI})$ is a reliable measure of the respiratory centre activity $[9,11-21,33-36]$. In the present study, chemoresponsiveness, expressed in terms of Edi response slope $\left(\Delta \mathrm{XP} / \mathrm{T}_{\mathrm{I}} / \Delta \mathrm{PCO}_{2}\right)$, increased from $\mathrm{C}$ to $\mathrm{A}(\mathrm{p}<0.028 \mathrm{KWAV})$. These findings are somewhat consistent with previous results by GRIBBIN and co-workers [10, 14]. The results obtained in the hypercapnic patients deserve two further commments. Firstly, about 20 yrs ago, in two groups of COPD patients with (group B) and without (group A) hypercapnia, but with more severe mechanical impairment in group B, Lourenço and Miranda [22] noted that the Edi response to $\mathrm{CO}_{2}$ was significantly lower in group B relative to a non-age-matched normal control group, whilst in group A it was higher. At variance with the findings of LOURENÇO and Miranda [22], in the present study it was found that Edi activity did not differ between the hypercapnic patients and the control group.

We have previously described [9] the methodological differences between the present study and that of LOURENÇO and Miranda [22]. We think that the low total integrated Edi activation observed by Lourenço and Miranda in the hypercapnic patients is due, at least in part, to the shorter TI often exhibited by these patients $[6,8,9,17,37]$. With the present method, however, both an increase in peak (XP) activity and a shorter TI contributed to the progressive increase in Edi $\left(\mathrm{XP} / \mathrm{T}_{\mathrm{I}}\right)$ from $\mathrm{C}$ to $\mathrm{A}$ (tables 2 and 4). Secondly, adaptive changes are involved in $\mathrm{CO}_{2}$ responsiveness. These depend on whether or not COPD patients retain $\mathrm{CO}_{2}$. Hypercapnics show adaptive changes characterized both by a shift of the $\mathrm{CO}_{2}$ threshold to the right, and a lowering of $\mathrm{P} 0.1$ to $\mathrm{CO}_{2}$ response slope (3-5). The methods commonly used in assessing $\mathrm{CO}_{2}$ responsiveness ( $\left.\dot{\mathrm{V}}_{\mathrm{E}}, \mathrm{P}_{0.1}\right)$ do not, however, allow firm conclusions to be drawn on whether the apparent reduction in $\mathrm{CO}_{2}$ responsiveness in hypercapnic COPD patients is necessarily due to a blunted responsiveness of central origin [7]. With the present EMG method we did not find either a reduction in Edi response slope (with the exeption of patients No. 17) or a consistent rightward shift in $\mathrm{PaCO}_{2}$ threshold in hypercapnic patients; instead, the Edi response slope was similar to that of normal subjects. Therefore, chemoresponsiveness did not appear to be subnormal in hypercapnic COPD patients. Nonetheless, looking at the data of $8.65 \mathrm{kPa}$ of $\mathrm{PCO}_{2}$ one has also to consider the following: 1) $\dot{V}_{E}$ was smaller in $B$ than in C, whilst Edi was similar and 2) in contrast, in group A, VE was similar but Edi significantly greater than in C. Based on these findings the question arises of whether Edi was adequate to sustain ventilation in hypercapnic COPD. In other words, we do not exclude the possibility that in some patients an inherent low $\mathrm{CO}_{2}$ responsiveness was also a contributory factor to hypercapnia.

The amount of Edi activity at $\mathrm{PCO}_{2}$ of $8.65 \mathrm{kPa}$ in COPD patients with or without chronic hypercapnia but similar mechanical abnormalities might depend on two principal factors. Firstly, different buffering capacity. If we assume that in the two groups there was the same difference in $\mathrm{HCO}_{3}^{-}$at $\mathrm{PCO}_{2}$ of $8.65 \mathrm{kPa}$ as we noted during room air breathing, this factor is likely to play a role. In fact, for a given level of $\mathrm{PCO}_{2}$ the greater the content of $\mathrm{HCO}_{3}^{-}$the lower the hydrogen ion activity and vice versa [38]. The significant relationship we found between Edi and $\mathrm{HCO}_{3}$ - in patients (fig. 3) seems to be consistent with this hypothesis. Secondly, chronic hypoxaemia. In chronic hypoxaemic-hypercapnic COPD patients and in normoxic-normocapnic COPD patients, hyperoxic condition appeared to result in a similar reduction in the hypoxic drive [8]. If this applies to the conditions of the present study, the neutral respiratory drive (NRD) would be underestimated in both groups. However, as shown in the study by LOURENÇo and Miranda [22], the hyperoxic condition imposed by $\mathrm{CO}_{2}$ rebreathing did not seem capable of modifying the NRD. In fact, during rebreathing with air and oxygen in concentrations adjusted to maintain the resting value of oxygen saturation, values of diaphragmatic response similar to those found with $100 \%$ oxygen were observed. In agreement with this, in the paper of BRADLEY et al. [6] hypoxic-normocapnic patients had similar $\Delta \mathrm{P}_{0.1} / \Delta \mathrm{PCO}_{2}$ response slopes to normoxic-normocapnic patients with similar obstruction and hyperinflation. Therefore, chronic hypoxaemia is not likely to play a major role in the differences observed.

Another point which needs to be discussed concerns the reliability of the mouth occlusion pressure as an index of neuromuscular respiratory drive under the present experimental conditions. Criticism concerns the possibility that: 1) in this condition the relaxation of abdominal muscles may take place only a few milliseconds before inspiration starts, preventing $\mathrm{P}_{0.1}$ from reflecting diaphragmatic electromyographic activity [39]; 2) 
abnormalities in lung and or chest wall mechanics may change the coupling of neural to muscular events [14, $21,28]$, i.e. for a given degree of Edi activity the greater the pulmonary volume the lower the inspiratory muscle force; and 3) in COPD patients, inspiratory muscle overloading is likely to occur because of pulmonary hyperinflation and intrinsic positive end expiratory pressure (PEEP). Intrinsic PEEP (PEEPi) imposes an extra burden on the inspiratory muscles [40]. In fact, during inspiration the early part of the pressure that the inspiratory muscles generate (Pmus) is spent counterbalancing PEEPi. In these conditions, the measurement of $\mathrm{P}_{0.1}$ would occur over a less advantageous portion of the length tension relationship of the inspiratory muscles.

On the other hand, several lines of evidence indicate that a low mouth pressure response relative to Edi response may be considered as indicative of a low relationship between input and output signals of the system [19, 21 , $28,37,41]$. The observation that, irrespective of a normal $\Delta \mathrm{Edi} / \Delta \mathrm{PCO}_{2}, \Delta \mathrm{P} 0.1 / \Delta \mathrm{PCO}_{2}$ was lower in group $\mathrm{B}$ patients than in either $\mathrm{A}$ or $\mathrm{C}$ groups seems consistent with the finding of a lower MIP in group B and to indicate a reduced inspiratory muscle ability to generate pressure in the face of a normal chemoresponsiveness. We interpret the similarity of MIP-normalized $\mathrm{P} 0.1$ response to $\mathrm{PCO}_{2}$ in the three groups (see tables 2 and 4 ) in this sense.

In conclusion, our data show that $\mathrm{CO}_{2}$ responsiveness is high in normocapnics, whilst in hypercapnics, though similar to that of the normal control group, it is probably inadequate to sustain ventilation.

\section{References}

1. Whitelaw WA, Derenne JP, Milic-Emili J. Occlusion pressure as a measure of respiratory center output in conscious man. Respir Physiol 1975; 23: 181-199.

2. Gelb AF, Klein E, Schiffman P, Lugliani R, Aronstam P. Ventilatory response and drive in acute chronic obstuctive pulmonary disease. Am Rev Respir Dis 1977; 116: 9-16.

3. Altose MD, McCauly WC, Kelsen SG, Cherniack NS. Effects of hypercapnia and inspiratoy flow-restive loading on respiratory activity in chronic airway obstruction. $J$ Clin Invest 1977; 59: 500-507.

4. Maranetra N, Pain MCF. Ventilatory drive and ventilatory response during rebreathing. Thorax 1974; 29: 578-581.

5. Matthews AW. The relationship between central carbon dioxide sensitivity and clinical features in patients with chronic airways obstruction. Q J Med 1977; 182: 179-195.

6. Bradley CA, Fleetham JA, Anthonisen NR. Ventilatory control in patients with hypoxemia due to obstructive lung disease. Am Rev Respir Dis 1979; 120: 21-30

7. Park SS. Respiratory control in chronic obstructive pulmonary disease. Clin Chest Med 1980; 1: 73-83.

8. Sorli J, Grassino A, Lorange G, Milic-Emili J. Control of breathing in patients with chronic obstructive lung disease. Clin Sci Mol Med 1978; 54: 295-305.

9. Gorini M, Spinelli A, Ginanni R, Duranti R, Gigliotti F, Scano G. Neural respiratory drive and neuromuscular coupling in patients with chronic obstructive pulrnonary disease (COPD). Chest 1990; 98: 1179-1186.

10. Gribbin HR, Gardiner IT, Heinz III GJ, Gibson GJ, Pride NB. Role of impaired inspiratory muscle function in limiting the ventilatory response to carbon dioxide in chronic airflow obstruction. Clin Sci 1983; 64: 487-495.

11. Lopata M, Zubillaga G, Evanich MJ, Lourenco RV. Diaphragmatic EMG response to isocapnic hypoxia and hyperoxic hypercapnia in humans. J Lab Clin Med 1978; 91: 698-709.

12. Evanich MJ, Lopata M, Lourenco RV. Analytical methods for the study of electrical activity in respiratory nerves and muscles. Chest 1976 (Suppl.); 70: 158-162.

13. Evanich MJ, Bruce E, Eldridge FL et al. Conference report: workshop on assessment of respiratory control in humans: IV. Measurement of the electrical activity in respiratory muscles. Am Rev Respir Dis 1977; 115: 541-548.

14. Gribbin HR, Pride NB, Bye PT, Di Maria G, Wang YT. Electrical activation of the diaphragm during stimulated breathing in patients with severe chronic airflow limitation and $\mathrm{CO}_{2}$ retention. Chest 1984; 85: (Suppl.) 50S-51S.

15. Scano G, Duranti R, Spinelli A, Gorini M, Lo Conte C, Gigliotti F. Control of breathing in normal subjects and in patients with chronic airflow obstruction. Bull Eur Physiopathol Respir 1987; 23: 209-216.

16. Gigliotti F, Duranti R, Fabiani A, Schiavina M, Scano G. Suppression of ventilatory muscle activity in healthy subjects and COPD patients with negative pressure ventilation (NPV). Chest 1991; 99: 1186-1192.

17. Scano G, Gigliotti G, Duranti R, Spinelli A, Gorini M, Schiavina M. Changes in ventilatory muscle function with negative pressure ventilation in patients with severe COPD. Chest 1990; 97: 322-327.

18. Sieck GC, Mazar A, Belman MJ. Changes in diaphragmatic EMG spectra during hyperpneic loads. Respir Physiol 1985; 61: 137-152.

19. Gorini M, Spinelli A, Gigliotti F, Duranti R, Arcangeli $\mathrm{P}$, Scano G. Changes in neural drive (EMGd) and neuromuscular coupling during histamine-induced bronchoconstriction in patients with asthma. Eur Respir J 1988; 1: 691-698.

20. Begle RL, Skatrud JB, Dempsey JA. Ventilatory compensation for changes in functional residual capacity during sleep. J Appl Physiol 1987; 62: 1299-1306.

21. Lopata M, Onal E, Cromydas G. Respiratory load compensation in chronic airway obstruction. J Appl Physiol 1985; 59: 1947-1954.

22. Lourenço RV, Miranda JM. Drive and performance of the ventilatory apparatus in chronic obstructive lung disease. $N$ Engl J Med 1968; 279: 53-59.

23. American Thoracic Society. Chronic bronchitis, asthma and pulmonary emphysema. A statement by the committee on diagnostic standards for nontuberculous respiratory disease. Am Rev Respir Dis 1962; 85: 762-768.

24. Scano G, Garcia Herreros P, Stendardi D, Degre S, De Coster A, Sergysels R. Cardiopulmonary adaptation to exercise in coal miners. Arch Environ Health 1980; 35: 360-366.

25. European Community for Coal and Steel. Standardization of lung function test. Bull Eur Physiopathol Respir 1983; 19: 1-95.

26. Peterson DD, Pack AI, Silage DA, Fishman AP. Effects of ageing on ventilatory and occlusion pressure responses to hypoxia and hypercapnia. Am Rev Respir Dis 1981; 124: 387-391.

27. Gross D, Grassino AE, Ross WR, Macklem PT. Electromyogram pattern of diaphragmatic fatigue. J Appl Physiol: Respirat Environ Exercise Physiol 1979; 46: $1-7$. 
28. Grassino A, Goldman MD, Mead J, Sears TA. Mechanics of the human diaphragm during voluntary contraction: statics. J Appl Physiol: Respirat Environ Exercise Physiol 1978; 44: 829-839.

29. Read DJC. A clinical method for assessing ventilatory response to carbon dioxide. Aust Ann Med 1967; 16:20 32.

30. Scano G, Gigliotti F, Spinelli A, Van Meerhaeghe A, Sergysels R. Breathing pattem and neuromuscular drive during $\mathrm{CO}_{2}$ rebreathing in normal man and in patients with COPD. Respiration 1986; 50: 73-82.

31. Halpem SL, Glenn MB, Goodhart RS. Special contribution. New height-weight tables; importance of new criteria. J Am Med Assoc 1960; 173: 134.

32. De Troyer A, Pride NB. The Respiratory System in Neuromuscular Disorders. In: Roussos C, Macklem PT, eds. The Thorax. New York: Marcel Dekker, 1985; 1089-1121.

33. Gigliotti F, Gurrieri G, Duranti R, Gorini M, Scano G. Effects of intravenous broxaterol on respiratory drive and neuromuscular coupling in COPD patients. Eur Respir J 1993; 6: 371-377.

34. Spinelli A, Marconi G, Gorini M, Pizzi A, Scano G. Control of breathing in patients with myasthenia gravis. Am Rev Respir Dis 1992; 145: 1359-1366.
35. Duranti R, Gheri RG, Gorini M, et al. Control of breathing in patients with severe hypothyroidism. Am J Med 1993; 95: 29-37.

36. Gorini M, Spinelli A, Ginanni R,et al. Neural respiratory drive and neuromuscular coupling during $\mathrm{CO}_{2}$ rebreathing in patients with chronic interstitial lung disease. Chest 1989; 96: 824-830.

37. Milic-Emili J, Siafakas NM, Gautier H. A new approach for clinical assessment of control of breathing. Bull Eur Physiopathol Respir 1979; 15: 17-26.

38. Goldring RM, Turino GM. Assessment of respiratory regulation in chronic hypercapnia. Chest 1976; 70 (Suppl.) 186-191

39. Grassino AE, Derenne JP, Almirall J, Milic-Emili J, Whitelaw W. Configuration of the chest wall and occlusion pressures in awake humans. J Appl Physiol: Respirat Environ Exercise Physiol 1981; 50: 134-142.

40. Haluszka J, Chartrand DA, Grassino AE, Milic-Emili J. Intrinsic PEEP and arterial $\mathrm{PCO}_{2}$ in stable patients with chronic obstructive pulmonary disease. Am Rev Respir Dis 1990; 141: 1194-1197.

41. Eldridge FL, Vaughn KZ. Relationship of thoracic volume and airway occlusion pressure: muscular effects. J Appl Physiol: Respirat Environ Exercise Physiol 1977; 43(2): 312-321. 